\title{
COMMENTS ON TUSHNET
}

SANFORD LEVINSON ${ }^{\dagger}$

\section{A DOSSIER ON \\ TAXONOMY OF GENERATION OF RIGHTS}

KEYWORDS: Fundamental Rights; Constitutionalism; Generations of Rights.

Palavras-Chave: Direitos Fundamentais; Constitucionalismo; Gerações de Direitos.

${ }^{\dagger}$ W. St. John Garwood and W. St. John Garwood Jr. Centennial Chair in Law, University of Texas Law School. Professor of Government, University of Texas at Austin. Visiting Professor of Law, Harvard Law School, Fall 2016 
What follows are some brief comments on Professor Tushnet's characteristically interesting set of reflections on the differences among different "generations" of rights. ${ }^{1}$ One way of conceiving these differences, of course, is the transition away from a "first generation" account privileging the protection of individuals from certain kinds of governmental overreaching. A canonical statement is found in Justice Louis Brandeis's famous dissent in the first case involving wiretapping that came before the Court in 1927. The framers of the Fourth Amendment, protecting persons against unreasonable searches, "conferred," Brandeis wrote, "as against the Government, the right to be let alone-the most comprehensive of rights and the right most valued by civilized men." ${ }^{2}$ It is no coincidence that Brandeis was also a great dissenter in cases involving freedom of speech, another area in which he privileged individual freedom. Second generation rights, on the other hand, scarcely emphasize the priority of the individual who yearns to be left alone by government. Instead, the emphasis on one the aid that government can provide individuals in need. One is made aware of all of the vulnerabilities that even the sturdiest of individuals may have with regard to enjoying what most people would regard as basic needs. These may include (though are not limited to) food, shelter, medical care, some degree of education, and the like.

Why not leave acquisition of such goods up to market transactions? The answer is all too simple: Many individuals simply do not have the financial resources needed to purchase them on the market. Even if one is inclined to hold individuals responsible for the "choices" they ostensibly make, it is impossible to apply such arguments, for example, to children. Moreover, as one develops more structural understandings of the economy, it becomes harder to hold individuals responsible for their loss of employment if they have been unlucky enough to be employed by old-fashioned businesses swept aside in a wave of the "creative destruction" attendant on the creation of new industries and ways of doing things or are the essentially helpless victims of the recessions and depressions that result from macro-economic developments well beyond their control. One might hope that private charities and other agencies of civil society would prove sufficient to help out those who are needy, but this has scarcely proved to be the case. And,

${ }^{1}$ Mark Tushnet, Notes on Some Aspects of the Taxonomy of "Generations" of Rights, 2 JOURNAL OF INSTITUTIONAL STUDIES 2 (2016).

2 Olmstead v. United States, 277 U.S. 438 (1928). It is telling, of course, that Brandeis was writing a dissenting opinion. It would be almost another forty years before the Supreme Court placed wiretapping under general judicial supervision.

2 JOURNAL OF INSTITUTIONAL STUDIES 2 (2016) 
therefore, we see the development of the modern welfare state, traceable back (at least) to Bismarckian Germany.

Welfare states can be defined in part by their willingness to supply goods to selected individuals or groups at below-market prices. Of necessity, this means that the goods, which do, after all, need to be paid for, even if not the recipients, are financed by transfers of wealth from haves to have nots. What justifies this is not any specific responsibilities that the former may have to specific members of the latter, but, rather, a mixture of the blunt fact that the haves possess resources that can be appropriated through taxation, coupled with a general view that to some extent we are all connected as joint members of society with some degree of responsibility for one another. The notion of the "family" widens from those with whom one shares a household or other kin relations to what is sometimes perhaps sentimentally described as "the human family." In any event, traditional notions of property rights, as Tushnet notes, inevitably become weakened as redistributive taxation becomes a more important subject (and object) of political discourse.

Many issues can become the focus of political argument without at the same time becoming "legalized." But the placement of rights in a constitution, unless they are carefully cordoned off as exclusively "aspirational," as in the Irish and Indian constitutions, inevitably invites litigation. Can a state in essence "refuse to rescue" a member of its community who is in need of basic resources? At least in traditional Anglo-American legal theory, there is no "duty to rescue." First-year torts students are always presented with drowning children who are simply ignored by strangers. Their parents almost certainly have a duty to rescue because of the nature of the parent-child relationship, but strangers have no such duty, even if the costs of rescue would be minimal. Needless to say, such harsh doctrines always generate vigorous discussion, especially when students are informed that what might be termed "protected indifference" to the welfare needs of others is extended to the state as well. As a matter of fact, states often mitigate their indifference by passing legislative programs, but the question under discussion in this exchange is what it means to place a duty on the state through constitutional design. It is, however, well worth discussing whether the passage of welfareconferring legislation raises most of the same problems thought to be presented by constitutionally-entrenched rights with regard, say, to the challenges facing judges called upon to enforce what may be broadly phrased statutes.)

Tushnet notes that constitutions are hardly self-enforcing. James Madison, perhaps the best-known "designer" of the U.S. Constitution, consistently expressed his doubts about the importance of what he called 
"parchment barriers." These could be fine phrases that were, however, likely to be ignored in the rough-and-tumble of actual political life. One might guarantee freedoms of speech and the press in the First Amendment to the U.S. Constitution, for example, but this did not stop the President and Congress in 1798, only seven years after the ratification of the Amendment, from passing a very harsh sedition law that criminalized criticism of the President and other speech bringing the national government into disrespect. The Supreme Court declared in 1965 that the law was unconstitutional, but that scarcely provided comfort to the newspaper editors who were tried and conflicted for its violation. Many other examples could be drawn from the constitutional history of the United States and, no doubt, probably all other constitutional systems.

A standard hope, of course, particularly of designers of liberal constitutions, is that an "independent judiciary" will enforce the barriers against governmental misconduct or, even more controversially, the duties placed on government to provide succor to the needy. Not only does this raise the problem that Tushnet alludes to: How are judges to be chosen, and why would one believe that their views about such matters would not generally conform with those of the officials appointing them (who may wish to suppress certain liberties or resist the taxation necessary to provide resources to the poor)? But even if one, perhaps by magic, creates a judiciary militantly supportive of second-generation rights, the question remains as to implementation in the face of legislative recalcitrance to spend the often immense amounts of money that secondgeneration rights inevitably require. A constitution may guarantee a whole panoply of goods, but it is not necessarily the case that the society itself is rich enough to finance all of them. As is often pointed out, some of the most impressive examples of textual second-generation rights appear in the constitutions of countries that are struggling economically. Think only of the South African and Iraqi constitutions in this regard, though surely there are many others. Choices may have to be made not only between welfare goods and, say, military weaponry for national defense, but among the welfare goods themselves. At what point does one stop spending on housing or medical care in order to pay for education or a minimum basic income for the elderly who either cannot work at all or who are entitled, after many years of hard work, to a dignified retirement? It is hard to believe that there is anything in the specific training of those who become judges that makes them "experts" on making such determinations. As Tushnet suggests, these are precisely the hard choices to which we most commonly look to legislators to make. Perhaps we turn to judges because we no longer trust legislators. If so, 
that obviously is evidence a deep defect in the national polity itself.

But Tushnet is directing our attention to so-called "third-generation" rights. Some of these may generally be described as group rights attached to members of specific sub-communities within the larger society. (That is not true, however, of "environmental rights," which, however controversial, are usually not viewed as integral to safeguarding a particular sub-national group that feels vulnerable to a hegemonic outside culture.) Both first- and second-generation rights require no significant discussion of groups and any rights that might be possessed by an overall group. These become especially important if the group claims rights not only against the wider state, but also against defecting or oppositional members of the group itself. Is a religious group, for example, entitled to exemption from general laws of inheritance or the rights of women, even if some members of the group would far prefer adherence to the general norm? It is also significant that many of these "group rights" cases involve the education of the young. After all, groups cannot maintain themselves through time without highly self-conscious efforts to socialize youngsters into the specific practices and ways of looking at the world that allow us to identify specific groups. This is especially important with regard to language, as illustrated in a host of cases arising from Quebec regarding the ostensible priority that French has over English in Quebec. But language is only one part of what constitutes distinct cultures that, by definition, may differ profoundly from other groups that share space within a given overall polity. "Multiculutralism" has become a recognized reality in almost all countries of the world today. To be sure, there may be backlash in some countries against it; that is one meaning attributed to the recent triumph in the United States of Donald Trump or the decision of 52\% of the voting public in the United Kingdom to leave the European Union. But attempting genuinely to "turn the tide" of multicultural realities is likely to prove at least as futile as an attempt by King Canute to command the tides not to flow on their own schedule.

Once again, one may wonder at the mechanisms of actual implementation of such rights when they are actually quite controversial and indicative of what might actually be deep fissures within a particular country (like Canada). To the extent that "group rights" can serve as evidence of such fissures, then one almost invariably starts to wonder whether constitutions should speak of that ultimate form of a group right called "secession." In a recent article, Professor Tushnet's colleague Vicki Jackson has argued that constitutions are probably wise to remain silent about the possibility of secession, though, at the same time, she endorses the view that one ought not to reject secessionism out of hand as a 
possible solution, however regrettable, to problems facing divided societies. ${ }^{3}$ In a famous decision, after all, the Canadian Supreme Court seemed to suggest that even if Quebec does not possess a right unilaterally to secede from Canada, the rest of Canada might nevertheless be under a duty to negotiate with Quebec should that province clearly indicate a desire to go its own way. And as one looks around the contemporary world, one can observe a host of secessionist movements. If the United Kingdom successfully secedes from the European Union, it is certainly likely that there will be renewed efforts in Scotland to undo the Treaty of Union of 1709 and secede from the United Kingdom itself. Moreover, one can easily understand why Spain resolutely refuses to recognize the legitimacy of the new country of Kosovo, itself a breakaway entity, for fear that it might add to the legitimacy of those supporting Catalonian secession.

In the same volume, Professor Tushnet offered a brief overview of the kinds of issues that might well arise in any actual negotiations about secession. ${ }^{4}$ Although lawyers would certainly be needed to help draft the specific language of legislation or treaties implementing any secession, it is unclear that these same lawyers would be particularly helpful during the negotiations themselves touching on fundamental political issues, including the all-important issue of whether there really is sufficient unity among disparate groups to support maintenance of a union instead of fragmentation into separate countries, as was seen in the former Yugoslavia or, more peacefully, even in what was once Czechoslovakia. Obviously, the systematic violation of first- and second-generation rights can also provoke political resistance and create substantial discord. But I want to suggest that there may be special edge, so to speak, to at least some third-generation rights inasmuch as they call on a rhetoric that may end up denying the priority of an overarching community with transcendent claims.

These are very preliminary observations. Not only could much more be said, but it is also certainly the case that I might modify my own views in light of further discussion. The point, though, is that Professor Tushnet is raising questions that should be of interest to anyone interested either in the general topic of "constitutional design" or some of the unhappy

${ }^{3}$ Vicki Jackson, Secession, Transnational Precedents, and Constitutional Silences, in Sanford Levinson (ed.), NULLIFICATION AND SECESSION IN MODERN CONSTITUTIONAL THOUGHT (2016).

${ }^{4}$ Mark Tushnet, Secession as a Problem in Negotiation, in Sanford Levinson (ed.), NULLIFICATION AND SECESSION IN MODERN CONSTITUTIONAL THOUght (2016), p. 343358.

2 JOURNAL OF INSTITUTIONAL STUDIES 2 (2016) 
realities of contemporary politics in a number of different countries across the globe.

\section{REFERENCES}

Mark Tushnet, Notes on Some Aspects of the Taxonomy of "Generations" of Rights, 2 JOURNAL OF INSTITUTIONAL STUDIES 2 (2016).

Mark Tushnet, Secession as a Problem in Negotiation, in Sanford Levinson (ed.), NulLificATION AND SECESSION IN MODERn CONSTITUTIONAL THOUGHT (2016).

Vicki Jackson, Secession, Transnational Precedents, and Constitutional Silences, in Sanford Levinson (ed.), NULLIFICATION AND SECESSION IN Modern CONSTITUTIONAL THOUGHT (2016).

Comments on Tushnet Comentários sobre Tushnet Submitted: 2016-12-07 